\title{
PREVALENCIA DE CATARATA E GLAUCOMA EM CRIANÇAS COM SINDROME NEFROTICA SOB CORTICOTERAPIA SISTEMICA
}

\section{Pôster}

Autores deste trabalho:

Maria Cristina de Andrade: UNIFESP-EPM

Leão FVF: UNIFESP-EPM

Borba PD: UNIFESP-EPM

Godoy BR: UNIFESP-EPM

Morais NSB: UNIFESP-EPM

Cançado MAP: UNIFESP-EPM

Área do Trabalho: Pediatria

Número de inscrição: 5597

Data da submissão:01/09/2016 às 10:09

\section{Justificativa}

A Síndrome Nefrótica (SN) em crianças tem prevalência de 16 para cada 10000 crianças. $\mathrm{O}$ tratamento geralmente requer corticoterapia sistêmica (CS) por tempo prolongado. Em adultos, o uso prolongado de CS pode causar catarata subcapsular posterior (SCP) e nuclear, exoftalmo, e/ou aumento da pressão intraocular (PIO) que pode resultar em glaucoma ou pode ocasionalmente causar danos ao nervo óptico

\section{Objetivo(s)}

Avaliar a prevalência de catarata, glaucoma e demais efeitos colaterais oculares em crianças com SN sob CS.

\section{Método(s)}

30 pacientes com SN do ambulatório de Nefrologia Pediátrica foram prospectivamente avaliados no Departamento de Oftalmologia e Ciências Visuais. Os pacientes foram submetidos à medida da melhor acuidade visual corrigida, tonometria de aplanação, biomicroscopia anterior e de fundo e fundoscopia indireta. 


\section{Resultado(s)}

A idade média dos pacientes foi de 11,36 \pm 7,36, com PIO média de (27 pacientes) 13,86 $\pm 2,60 \mathrm{mmHg}$ no olho direito e $14,18 \pm 2,66 \mathrm{mmHg}$ no olho esquerdo; 4 pacientes tinham catarata subcapsular posterior (SCP) incipiente em ambos os olhos, e um paciente tinha catarata SCP em um olho, totalizando 9 em 60 olhos avaliados (prevalência de 15\%); um paciente $(1,6 \%)$ tinha aumento da escavação do disco óptico $(0,8$ nos dois olhos); todos os pacientes tinham acuidade visual corrigida de 20/25 ou melhor em ambos os olhos. Apenas 9 pacientes estavam sob CS no momento da avaliação (30\%).

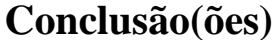

CS é um fator de risco bem estabelecido para o desenvolvimento de catarata subcapsular posterior, glaucoma e/ou aumento da PIO. O estudo revelou alta prevalência de catarata subcapsular (15\%), semelhante ao encontrado na literatura $(14,7 \%)$. Elevação da PIO pode ocorrer numa porcentagem de pacientes sob CS. Nenhuma criança tinha queixa visual e baixa acuidade visual. Embora o valor médio da PIO não tenha sido elevado, um paciente tinha aumento da escavação do nervo óptico em ambos os olhos. Apesar dos efeitos colaterais oculares da CS serem raros, o impacto de catarata e glaucoma no desenvolvimento visual de crianças torna necessário o encaminhamento para exame oftalmológico de toda criança em uso prolongado de CS. 